\title{
COMUNICAÇÃO
}

\section{NOVO CASO DE DIROFILARIOSE PULMONAR HUMANA ADQUURIDA NO BRASIL}

\author{
Valdir Sabbaga Amato, Vicente Amato Neto, \\ David Everson Uip e Marcos Boulos
}

\begin{abstract}
A dirofilariose pulmonar humana, zoonose descrita pela primeira vez em 1961, é usualmente ocasionada pela Dirofilaria immitis, nematóide que se aloja no coração direito de cães, infectando o homem através da picada de mosquitos dos genêros culex, Aedes ou Anopheles ${ }^{4}$. É doença incomum, autolimitada e, quando presente, tem como conotação principal o diagnóstico diferencial que suscita.
\end{abstract}

Essa modalidade de verminose, algumas vezes assintomática, pode motivar dor torácica, tosse, hemoptise, dor na garganta, sibilo, calafrio, febre, dispnéia dependente de esforço, fadiga, síncope e emagrecimento ${ }^{1}$. Na investigação, processos reveladores por imagem mostram acometimentos constituídos por nódulos únicos ou em pequeno número, confundiveis, por exemplo, com câncer metastático, hamartomas, cistos e danos colagenóticos. Quanto às provas sorológicas, até o momento não há suficiente padronização para permitir uso relacionado com pacientes, sendo o diagnóstico definitivo obtido pelo exame anatomopatológico de tecido pulmonar, geralmente por meio de toracotomia.

A maior quantidade de eventos concernentes à enfermidade em questão foi evidenciada nos Estados Unidos da América do Norte. Quanto ao Brasil, estão publicados até o momento, dois casos autóctones ${ }^{15}$ e nove outros encontram-se notificados em anais de congresso ${ }^{2}$.

\section{Descrição do caso}

No início do mês de agosto, em 1994, fomos procurados por M.M.S., do sexo

\footnotetext{
Instituto Paulista de Doenças Infecciosas e Parasitárias, São Paulo, SP.

Endereco para correspondência: Dr. Valdir Sabbaga Amato. Instituto Paulista de Doenças Infecciosas e Parasitárias. Alameda Gabriel Monteiro da Silva 429, 01442-000 São Paulo, SP.

Recebido para publicação em 19/10/94.
}

feminino com 60 anos de idade, branca, casada, e brasileira, tendo prendas domésticas como ocupação. Residia na cidade de São Paulo (SP) e referiu viagens freqüentes à cidade de Ubatuba, situada no litoral do citado Estado de São Paulo, onde possuía vários cães. Ela desejava orientação terapêutica pois, após toracotomia com biópsia pulmonar efetuada 13 dias antes, houve constatação da existência de dirofilariose, no Hospital Israelita "Albert Einstein" (São Paulo, SP), de acordo com exame anatomopatológico cuja descrição transcrevemos a seguir: à macroscopia, presença de nódulo pulmonar constituído de tecido avermelhado, elástico e medindo $2,0 \mathrm{x}$ $1,7 \mathrm{~cm}$; à microscopia, pulmão exibindo área de necrose contendo restos calcificados de um nematóide identificado como Dirofilaria immitis, vendo-se ao redor infiltrado inflamatório composto por células epitelióides, eosinófilos, linfócitos e células gigantes de Langhans.

A toracotomia ocorreu em virtude do encontro de nódulo sólido localizado em topografia apical no lobo pulmonar superior à esquerda (Figura 1). Não havia qualquer sintomatologia e os exames radiológico e tomográfico computadorizado do tórax tiveram lugar para controle de dirofilariose anterior, porque em novembro de 1992 adoeceu, sucedendo tosse sem expectoração como manifestação. Então, avaliações por Raio x e tomografia evidenciaram duas lesões nodulares no segmento basal posterior do lobo inferior direito, em situação periférica, medindo a maior aproximadamente $2,0 \mathrm{~cm}$ em seu máximo diâmetro transverso (Figura 2); efetuada toracotomia para diagnóstico, ao exame anatomopatológico ("Locus - Anatomia Patológica e Citologia", São Paulo, SP) comprovou-se: à macroscopia, fragmentos nodulares de tecido, medindo 1,7 e $1,1 \mathrm{~cm}$ nas maiores dimensões, tendo a superfície externa de aspecto levemente esponjoso e cor acastanhada; à microscopia, fragmentos pulmonares com presença de parasitas 
Comunicação. Amato VS, Amato Neto V, Uip DE, Boulos $M$. Novo caso de dirofilariose pulmonar humana adquirida no Brasil. Revista da Sociedade Brasileira de Medicina Tropical 28:285-286, jul-set, 1995.

necróticos intravasculares, tromboses vasculares, focos de necrose com reação inflamatória crônica e supuração (dirofilariose).

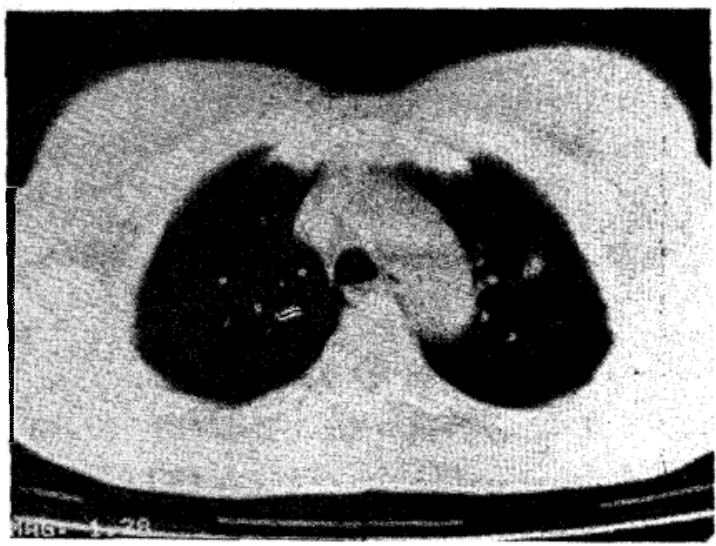

Figura 1 - Tomografia computadurizada de tórax. obseria-se pequeno nódulo sólido localizado em topografia apical do lobo pulmonar superior a esquerda clestitudo de ombs comemorations de natureza patologica.

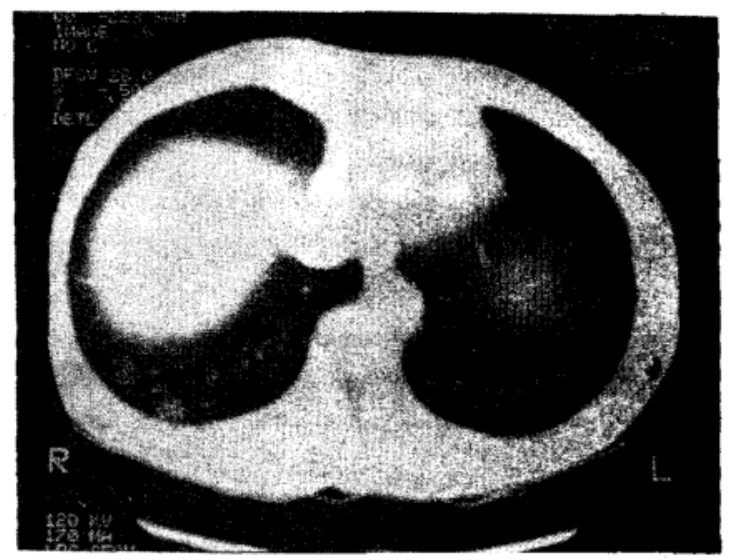

Figura 2. Tomegrafia computadorizada do törax. Presenca de duas lesoes nodulares no segmento basal posterior do lobo inferior direito, en situaçäo periférica, a maior delas medindo aproximadamente $2,0 \mathrm{~cm}$ em seu maior diametro transuerso.
Em face ao que constatamos na literatura médica, decidimos não instituir qualquer tratamento. Optamos por observação e valorizamos o caráter benigno da enfermidade, agindo de maneira igual à adotada quando reconhecemos e divulgamos outro adoecimento semelhante'.

A dirofilariose teve confirmação irrefutável em 1992 e 1994. Na segunda ocorrência o cirurgião que indicou a toracotomia não valorizou o que aconteceu previamente. Contudo, a obtenção de novo diagnóstico, idêntico, cria situação para a qual não encontramos cabal explicação. Talvez durante estes dois anos tenha passado desapercebido um nódulo ou a lesão, em evolução. Por outro lado, admitir que se deu mais uma infecção na mesma pessoa é, quiçá, pouco prudente, se lembrada a extrema raridade do encontro de dirofilariose humana, pelo menos diante do que se conhece no momento.

\section{REFERÊNCIAS BIBLIOGRÁFICAS}

1. Amato Neto V,Amato VS, Moraes Júnior ACP, Cerri GG. Dirofilariose pulmonar humana, adquirida no Brasil: comunicação de um caso. Revista do Instituto de Medicina Tropical 35: 457-460, 1993.

2. Barbas Filho, JV, Barbas CSV, Tucci MR, Jatene F, Milanez JR, Curi N. Human pulmonary dirofilariosis: study of nine cases. American Review Respiratory Diseases 145:A550, 1992.

3. Dashiell GP. A case of dirofilariasis involving the lung. The American Journal of Tropical Medicine and Hygiene 10:37-38, 1961.

4. Lawrence T, Glickman VMD, Grieve RB, Schntz PM. Serologic diagnosis of zoonotic pulmonary dirifilariosis. The American Journal of Medicine 80:161-164, 1986.

5. Saad JR, Ethel Filho J, Próspero JD, Dorgan Neto V, Aguiar Neto, JR. Dirofilariose pulmonar - relato de um caso. Jornal de Pneumologia 17:90-93. 1991. 